\title{
Effects on Pharmaceuticals in the Environment - an Overview and Principle Considerations
}

P. Pfluger - D. R. Dietrich

For the 2684 and more than 3000 pharmaceutical compounds registered in Germany (Rote Liste 2000) and Great Britain (Ayscough et al. 2000), respectively, the predominant proportion of the available information is characterised by data from preclinical and clinical studies. These data and respective peer- and non-peer reviewed literature can either be retrieved from the pharmaceutical companies themselves or in a more concentrated fashion from on-line databases, e.g. Toxnet (http://www.sis.nlm.nih.gov/ ToxSearch.cfm), which includes information from databases such as HSDB, Genetox, Toxline etc., and from literature databases, e.g. MedLine, Biosis and Embase. Little information can be found, however, on the fate, transport and effects of these pharmaceuticals once they have been released into the environment (direct disposal and/or indirect disposal via sewage treatment plants, STPs). This paucity of data raises several questions: do the pharmaceuticals reach the environment and in what quantity? What are the known and potential acute, subchronic and chronic adverse effects of these compounds in exposed environmental species and the ecosystem as a whole?

\section{1}

\section{Occurrence of Pharmaceuticals in the Environment}

Due to a lack of concern regarding the occurrence and effects of pharmaceuticals in the environment, no data appears in the literature until the middle of the 1970s. Then, one of the first reports concerned with pharmaceuticals in the environment was published by Garrison et al. (1976). Using GC/MS technology, they reported the presence of clofibric acid in the effluent of the Big Blue River sewage treatment plant in Kansas City, USA. Up to $2 \mu \mathrm{g}^{-1}$ clofibric acid were determined in raw and treated sewage waters. These concentrations were corroborated shortly thereafter by Hignite and Azarnoff (1977), who reported the presence of clofibric acid and salicylic acid at concentrations of up to $10 \mu \mathrm{g} \mathrm{I}^{-1}$ and $96 \mathrm{\mu g} \mathrm{l}^{-1}$ in sewage effluent. In view of the more recent analyses of sewage treatment effluents, which concurrently find the latter compounds in a concentration range approximately one order of magnitude lower (Stan et al. 1994; Heberer and Stan 1996; Heberer et al. 1997; Ternes 1998; Ternes et al. 1999a), the concentrations reported by Hignite and Azarnoff appear to be a little high. Indeed, the analyses of pharmaceuticals in environmental samples are apparently not a matter of triviality, but rather demand the highest attention as to sample preparation and treatment (Ternes et al. 1998). Due to the improved analytical techniques available as of the 1990s, the number of pharmaceuticals detected in environmental samples, mostly in sewage treatment effluents and rivers but also in ground- and drinking water (Heberer et al. 1997; Heberer et al. 1998), increased almost exponentially. 
One of the major problems associated with the values obtained from the analyses of environmental samples is that the total influx of pharmaceuticals and the actual retention of the respective compounds in the sewage treatment plants are still difficult to quantify. The quantification of pharmaceuticals in raw sewage water as well as the calculation of retention in the sewage treatment plants would provide a better basis for environmental risk assessment. Presently the total influx of pharmaceuticals into sewage treatment plants can only be estimated using average patient dosing data and prescription information, as information regarding production amounts of pharmaceuticals in Germany and other European countries is not open to the public. One approach to classify and quantify the total amounts of prescribed pharmaceuticals in Germany was carried out by Schwabe and Paffrath (1996). They multiplied the average amount of daily doses with the (available) number of prescribed daily doses per year. However, the calculated weight in tonnes per year underestimated the real amount, as it did not include veterinary pharmaceuticals and human pharmaceuticals prescribed in hospitals or sold over the counter (OTC products). Henschel et al. (1997) estimated the use of a number of pharmaceuticals in Germany and came to the conclusion that, e.g. between 95 and 315 tonnes of salicylic acid reached the sewage treatment plants in 1994 . Indeed, of the pharmaceuticals which predominate in the analyses of environmental samples as well as the lists compiled from prescription data, most belong to the class of analgesics (NSAIDs), antibiotics, hypotensives, antiasthmatics, diuretics and psycholeptics (Halling-Sørensen et al. 1998; Hartmann et al. 1998; Ternes 1998; Ternes et al. 1999a; Hirsch et al. 1999; Stuer-Lauridsen et al. 2000).

Pharmaceuticals are released into raw sewage and subsequently into the aquatic environment either as non-metabolised parent compounds or entirely as metabolites. As mammalian metabolism of the parent compound and excretion as well as the biodegradability of the parent compound or its primary metabolites are compound specific, the sewage treatment plant retention and environmental fate of pharmaceuticals has be to investigated on a case-by-case basis, as outlined in the recent review by Ayscough et al. (2000)

The need for the additional detection of metabolites is exemplified by clofibric acid. The active substance, clofibrate, could not be detected in sewage effluent and river water. Clofibric acid, however, its major metabolite, was found in significant amounts in the same study (Ternes 1998). Other commonly detected metabolites include salicylic acid, the major metabolite of the analgesic acetylsalicylic acid (Hignite and Azarnoff 1977; Ternes 1998), or dehydrated erythromycin, major metabolite of the antibiotic erythromycin (Hirsch et al. 1999). Most of the current information was obtained by a relatively small number of researchers, e.g. Kümmerer et al. (see Chap. 4,7, and 19), Richardson and Bowron (Richardson and Bowron 1985), Ternes et al. (Ternes 1998; Ternes et al. 1998; Ternes et al. 1999a; Ternes et al. 1999b; Stumpf et al. $1996 \mathrm{a}, \mathrm{b})$.

Although the formidable advancement in analytical techniques provides better detection of parent compounds and metabolites, the greatest problem posed by pharmaceuticals in the environment lies in the fact that practically nothing is known about the environmental hazard of either the parent compounds or metabolites, as discussed below.
2.2

\section{Environmental Effects of Pharmaceuticals on}

Organisms and Ecosystems

In view of the trace amounts of pharmaceuticals and their metabolites found in the environment, the question may be asked, whether it is sensible and feasible to assess potential adverse effects in exposed organisms and ecosystems. The problem, however, lies in the fact that these compounds are released from a point source (STP) and always occur as mixtures. In addition, the constant release, albeit at varying levels of concentration, provides for a chronic rather than an acute exposure scenario in the respective species and ecosystem exposed. Indeed, a recent review of the published literature on potential adverse effects of pharmaceuticals in aquatic organisms (Dietrich et al. 1998b) highlighted the paucity of data for single compounds while demonstrating the absolute lack of data on the effects of mixtures. Most of the information available on cornpounds such as $\beta$-blockers (metoprolol, propanolol), lipid regulators (clofibrate, bezafibrate), NSAIDs (diclofenac, ibuprofen, indomethacin, naproxen) and antibiotics (roxithromycin, trimethoprim, sulfamethoxazol) dealt with the medical use of these substances, i.e. preclinical (experimental data from rodents) and clinical studies and patient case studies. At best, data was available for Daphnia magna 48 hour immobilisation tests or zebrafish (Danio rerio) embryotoxicity tests (Henschel et al. 1997; Dietrich et al. 1998b), making any form of environmental risk assessment a questionable affair. Most currently available data on the effects of pharmaceuticals in the environment were obtained using standard test systems/procedures, e.g. algal growth inhibition tests (OECD 1984a), the Daphnia magna acute and chronic toxicity test (OECD 1984b) or embryotoxicity tests with zebrafish (DRETA, Danio rerio embryo teratogenesis assay; Dietrich et al. 1998c; Dietrich and Prietz 1999) and the African clawed frog Xenopus laevis (FETAX, frog embryo teratogenesis assay Xenopus, (ASTM 1991). An excellent overview on the present information was recently produced in the form of the Technical Report $P_{3} 90$ by the British Environment Agency (Ayscough et al. 2000). The question must be raised, however, whether the standard acute test systems are of any value for the assessment of potential adverse effects in organisms chronically exposed to lowest concentrations of pharmaceuticals and/or their metabolites.

2.2.1

\section{Risk Assessment}

As discussed above, any form of environmental risk assessment must contain the element of probable causality. A test system and its specific parameters and endpoints are useful for risk assessment purposes only if there is a reasonable chance that they could also occur in the organism(s) or ecosystem(s) of interest. In other words, it is not very meaningful to employ a microbial growth inhibition test to assess the "ecotoxicity" of $17 \alpha$-ethinyloestradiol, when all along it is clear that endocrinological endpoints and assays would be much more reasonable, relevant and sensitive. For example, the limits of classical ecotoxicology tests were revealed by a study of Henschel et al. (1997). Four pharmaceuticals and their respective metabolites were tested with 
different standard and non-standard ecotoxicology tests. The most sensitive tests were the non-standard tests, e.g. the BF-2 fish cell line (cytotoxicity and proliferation inhibition of fish cells). These tests all included relevant end points for the tested pharmaceuticals. All the classical standard tests, however, underestimated the toxicity of the four compounds. Hence, the choice of a relevant toxicity test is of great importance. The "right" test should include end points that detect effects associated with the specific mode of action of the chosen pharmaceutical. Most of the specific information regarding the mode of action, possible promising parameters as well as potential adverse (side) effects can be gleaned from the mammalian studies that have already been carried out for pharmaceutical registration and patient case studies. It is not suggested that the mammalian data can be directly extrapolated to the environmental situation; however, as a first point of entry for environmental risk assessment and experimental planning, these can be very helpful (Dietrich et al. 1998a,b,c; Dietrich and Prietz 1999).

\subsection{2}

\section{Use of Pharmaceuticals, Mode of Action and/or Adverse Side Effects in}

Mammals as a Basis for Studying the Potential Environmental Impacts

When using mammalian data as a starting base, it is surprising to note that a high proportion of the pharmaceuticals on the market present with side effects (Rittmannsberger 1990), including immunosuppression, endocrine activity, deregulation of neural activity, etc. In many cases these side effects occur only in a very small subset of patients or following prolonged exposure to the compound in question. Extrapolating to the environment, however, would entail a completely different scenario: as mixtures of pharmaceuticals and/or their metabolites will be the predominant form of exposure for the organisms, all single compounds would have to be evaluated for thei activity in a given endpoint, e.g. immunosuppression, vitellogenin induction and oestrogen receptor binding. Assuming additivity of the single activities, equivalen factors can be calculated and a Toxicity Equivalent Factor (TEF) approach implemented as has been the case for PCBs, Dioxin, Furans, etc. (Safe 1992, 1998). However, in order to do so, a prerequisite is to have the necessary basic understanding of the organisms and their normal physiological functions. For example, modulations of the immune svstem by pharmaceuticals have so far not been studied in aquatic organisms, more than likely due to a lack of proper understanding of the immune system, and consequently specific endpoints have not been established. One exception may be the case of antibiotics. Some of these substances have been in use in aquaculture to control for bacterial infections and as growth promoters (Moffitt 1991, 1998). As these antibiotics are of great economic importance in fish farming, their immunomodulating properties on fish were also partly studied (Lunden et al. 1998, 1999; Tafalla et al. 1999). Oxytetracycline, oxolinic acid and florfenicol, have demonstrated to produce a slight immunosuppression; however, whether this automatically implies that the organisms were more prone to pathogens and parasites has so far not been proven. More information on antibiotics is presented in Chap. 7 and Chap. 15 .

In contrast to the insufficient information on immunomodulation, a wealth of data is currently published on adverse effects of xenobiotics, including pharmaceuticals on the androgenic or oestrogenic system, specifically of aquatic species. Starting with descriptions of hormone-like effects of structurally different compounds in the 1940s, the innovative publications of McLachlan directed the attention of the scientific community, the government and the public to this topic (McLachlan 1980, 1985, 1993; McLachlan et al. 1984, 1987; McLachlan and Newbold 1987; McLachlan and Korach 1995). Subsequently, varying and sometimes contradictory information became available dealing with different aspects of endocrine modulation. Today, the mode of action of the hormone-mimicking compounds is one of the best-understood fields in ecotoxicology. Their overall environmental impact, however, remains to be evaluated. More information on this topic is presented in Chap. 6.

\section{3}

\section{Carbamazepine: An Example for Investigative Environmental Toxicology Using} Mammalian Data

A good example to illustrate the imbalance between analytical and toxicological data is carbamazepine (Fig. 2.1), a widely prescribed antiepileptic drug, which is ubiquitously present in the aquatic environment. Median values of $2.1 \mu \mathrm{g} \mathrm{l}^{-1}$ in German STP effluents and $0.25 \mu \mathrm{g} \mathrm{I}^{-1}$ in German rivers have been reported (Ternes 1998; Ternes et al. 1999a). Removal in sewage treatment plants was found to be extremely low $(7 \%)$, while the estimated prescription amount for 1995 in Germany was calculated to be 80 t (Schwabe and Paffrath 1996; Ternes 1998).

A recent literature review demonstrated a complete lack of ecotoxicological data for carbamazepine (Dietrich et al. 1998b). The analysis of the mammalian data in the literature suggested teratogenic effects and a possible antiandrogenic (oestrogenic) effect of carbamazepine. Juvenile rats treated for three months with carbamazepine presented with reduced prostate weight and decreased numbers of sperm (Dietrich et al. 1998b). Hence, a study was commissioned to investigate the potential toxicity and oestrogenic activity of carbamazepine in aquatic organisms (Pfluger et al. 2000). Both Daphnia magna immobilisation and zebrafish (D. rerio) and amphibian (X. laevis) embryotoxicity tests revealed a very moderate toxicity (teratogenicity and mortality in the $74-138 \mathrm{mg} \mathrm{l}^{-1}$ range. Furthermore, none of the expected oestrogenic effects (vitellogenin induction, increased ER expression, ER binding) could also be observed.

In addition to the above adverse effects in the mammalian studies, patient case studies indicated a possible immunosuppressive effect of carbamazepine, e.g. decreased IgA and IgM levels and increased natural killer-cell activity and phagocytosis (Garzon et al. 1986; Pacifici et al. 1991, 1992; Andrade-Mena et al. 1994; Andrade-Mena 1996) However, the results of the patient and rodent studies cannot be directly transferred to other organisms. Fish, for example, appear to lack IgA. Therefore, additional basic research on the immune system of fish has to be carried out before the potential immunosuppressive activities of carbamazepine can be properly evaluated.

Fig. 2.1. Carbamazepine

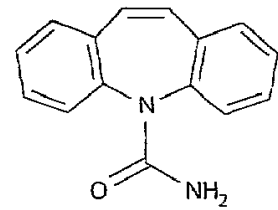




\section{3}

\section{A Final Perspective}

Most of the available literature on pharmaceuticals in the environment deals with the analytical detection of these compounds in the aquatic environment. For a very few of these chemicals, the environmental fate is known. Data on the effects of these compounds in environmentally relevant organisms are, however, rare. This lack of information should be completed for many of the substances detected in environmental samples. Nevertheless, it should be stressed that the currently available standardised ecotoxicological tests are not sufficient, as they can underestimate the potential hazards of a given compound. Specific tests, tailored to include the compound-specific mode of action of a given pharmaceutical, have to be carried out to provide a better basis for environmental risk assessment. In conclusion, ecotoxicology must change its position from the current conservative to a more mechanistically oriented point of view.

\section{References}

Andrade-Mena CE (1996) Immunodepression induced by carbamazepine administration is mediated by CD \&+ spleen T cells. Int I Tissue React 18(2-3):81-85

Andrade-Mena CE, Sardo-Olmedo JA, Ramirez-Lizardo EJ (1994) Effects of carbamazepine on murine humoral and cellular immune responses. Epilepsia 35(1):205-208

ASTM (1991) Standard guice for conducting the frog embryo teratogenesis assay-Xenopus (FETAX). E 1439-91. American Society for Testing and Materials, Philadelphia, USA, PP 1-11

Ayscough N, Fawell J, Franklin G, Young W (2000) Review of human pharmareuticals in the environ-

Dietrich $D$, kroll S, Schmid T, Rumpi S (1998a) Literaturrecherche zum Zusammenhang von UmweltBinnenkanal. Ami für Linweltschutz, St Gallen, Schweiz

Dietrich D, Schreiber H, Rump\{ S (1998b) Literaturrecherche zu Pharmaka im aquatischen Milieu. Environmental Toxicology, University of Konstanz, Konstanz

Dietrich DR, Prietz A (1999) Fish embryotoxicity and teratogenicity of pharmaceuticals, detergents and pesticides regularly detected in sewage treatment plant effluents and surface waters. Toxicol Sci $48(1-S): 151$ Dietrich DR, Prietz A, Kiamos MA (1998c) Danio rerio embryotoxicity and teratogenicity assay (DRETA) for detecting waterborne embryo-toxicants and teratogens. Toxicol Sci $42(1-S): 259$

Garrison All, Pope JD, Allen FR (1976) GC/MS analysis of organic compounds in domestic wastewaters. Garzon $\mathrm{P}$ Gonzalez-Cornejo S, Hernandez-Hernandez G, Aguirre-Portillo L, Almorores-Cuevas $C$ Navarro-Ruiz A (1986) Effects of antiepileptic drugs on concentration of serum proteins and immunoglobulins of epileptic patients. Gen Pharmacol $17(1): 49-55$

Halling-Sørensen B, Nielsen SN, Lanzly PF, Ingerslev E, Lützohfft HCH, Jorgensen SE (1998) Occurrence, fate and effects of pharmaceutical substances in the environment. A review. Chemosphere 36(2):357-393 Hartmann A, Alder AC, Koller T, Widmer RM (1998) Identification of fluoroquinone antibiotics as the main source of umu-C genotoxicity in native hospital wastewater. Enviren Toxicol Chem $17(3)$ : $377-38 z$

Heberer T, Stan HJ (1996) Vorkemmen von polaren organischen Kontaminanten im Berliner Trinkwasser Vom Wasser $86: 19-3$,

Heberer T, Dünnbier U, Reilich C, Stan HJ (1997) Detection of drugs and drug metabolites in ground water samples of a drinking water treatment plant. Fresenius Environ Buil 6:438-443

the aquatic system in Berlin. Pant $\mathrm{HJ}$ (1998) Occurrence and distribution of organic contaminants in and groundwater. Acta Hydroch Hydrob 26:272-278

Henschel KP, Wenzel A, Diedrich M, Fliedner A (1997) Environmental hazard assessment of pharmaceuticals. Regul Toxicol Pharmacol 25(3):220-225

Hignite C, Azarnoff DL (1977) Drugs and drug metabolites as environmental contaminants: chlorophenoxyisobutyrate and salicylic acid in sewage water effuent. Life Sci 20(2):337-34

(1999) Occurrence of antibiotics in the aquatic environment Sci Total Environ 225:109-118
Lunden T, Miettinen S, Lonnstrom LG, Lilius EM, Byiund G (1998) Influence of oxytetracycline and oxolinic acid on the immune response of rainbow trout (Oncorbynchus mykiss). Fish and Shellifish oxolinic acid on the ing

Lunden T, Miettinen S, Lonnstrom LG, Lilius EM, Bvlund G (1999) Effect of florfenicol on the immune response of rainbow trout (Oncorhynchus mykiss). Vet Immunol Immunopathol 67(4):317-25

McLachlan JA (1980) Estrogens in the environment. Elsevier, New York

MicLachlan JA (1985) Estrogens in the environment II. Influences on development. Elsevier, New York CcLachlan JA (1993) Functional toxicology: a new approach to detect biologically active xenobiotic Environ Health Perspect 101:386-387

McLachlan JA, Korach KS (1995) Symposium on estrogens in the environment III: Global health implications. Environ Health Perspect 103(Suppl 7):3-158

Derspect 75:25-27

McL achlan JA, Korach KS, Newbold RR, Degen GH (1984) Diethylstilbestrol and other estrogens in the environment. Fundam Appl Toxicol 4:686-691

achlan JA, Pratt RM, Markert CL (1987) Developmental toxicology: mechanisms and risk. Cold Spring Harbor Laboratory, Cold Spring Harbor (Banbury Report)

Moffitt CM (1991) Oral and injectable applications of erythromycin in salmonid fish culture. Vet Hun Toxicol 33(Suppl 1):49-53

Moffitt CM (1998) Field trials of investigational new animal drugs. Vet Hum Toxicol 4o(Suppi 2):48-52 ing of Chemicals 202

Pifici R, Paris L, Di Carlo S, Pichini S, Zuzccaro P (1991) Immunologic aspects of carbamazepine treatment in epileptic patients. Epilepsia 32(1)::222-127 mazepine in mice. Int I Immunopharmacol 14(4):605-611 Toxizität und zur endokrinen Aktivität von Carbamazepin. EUREGIO Ökotoxikologie Service Labor, Universität Konstanz, Konstanz

Che fate of pharmaceutical chemicals in the environment. J Pharm Pharmacol 37:1-12

(1990) Carbamazepine in the treatment of psychiatric diseases: effects and side efWien Med Wochenschr 140(15):398-404

Safe SH (1092) Development, validation and limitations of toxic equivalent factors. Chemosphere

$25(1-2): 61-64$
Safe $S H$ (1998) Hazard and risk assessment of chemical mixtures using the toxic equivalency factor approach. Environ Health Perspect 106(Suppl 4):1051-1058

Shwabe U, Paffrath D (1996) Arzneiverordnungsreport '96. Aktuelle Daten, Kosten, Trends und Kommentare. Gustav Fischer Verlag, Stuttgart, Jena (Drug prescription report ' 96 current data, costs,

Stan HJ, Heberer T, Linkerhägner M (1994) Vorkommen von Clofibrinsäure im aquatischen System Führt die therapeutische Anwendung zu einer Belastung von Oberflāchen-, Grund- und Trinkwasser? $83: 57-68$

Stuer-Lauridsen F, Birkved M, Hansen LP, Lützhøft H, Halling-Sørensen B (2000) Environmental risk assessment of human pharmaceuticais in Denmark after normal therapeutic use. Chemosphere 40:783-793 Stumpf M, Ternes TA, Haberer K, Baumann W (1996a) Nachweis von natürlichen und synthetischen Ostrogenen in Kläranlagen und Fliessgewässern. Vom Wasser 87:251-26

Stumpf M, Ternes TA, Haberer K, Seel P, Baumann W (1996b) Nachweis von Arzneimittelrückständen in Kläranlagen und Fließgewässern. Vom Wasser 36:291-303

Tafalla C, Novoa B, Alvarez JM, Figueras A (1999) In vivo and in vitro effect of oxytetracycline treatment on the immune response of turbot, Scophthalmus maximus (L). J Fish Dis 22(4):271-276

Tes TA (1998) Occurrence of drugs in German sewage treatment plants and rivers. Wat Res 32(11):3245-3260 well as betablockers and hetaz-s/mpthomimetics in aquens matrices using GC/MS and LCMS/MS. Fresenius J Anal Chem 362(3):329-340

Ternes TA, Hirsch RW, Stumpf M, Eggert T, Schuppert BF, Haberer K (1999a) Nachweis und Screening von Arzneimittelrückständen, Diagnostika und Antiseptika in der aquatischen Umwelt. ESWEInstitut fur Wasserforschung und Wassertechnologie $\mathrm{GmbH}$, Wiesbade

Ternes TA, Stumpf M, Muller J, Haberer K, Wilken RD, Servos M (1999b) Behaviour and occurrence of estrogens in municipal sewage treatment plants. I. Investigations in Germany, Canada and Brazil. Sci Total Environ 225:81-90 